\title{
First-trimester trophoblasts obtained by chorionic villus sampling maintain tolerogenic and proteomic features in successful pregnancies despite a history of unexplained recurrent pregnancy loss
}

Valentina Bruno, Robert Lindau, Maria Jenmalm, Carlo Ticconi, Emilio Piccione, Adalgisa Pietropolli and Jan Ernerudh

The self-archived postprint version of this journal article is available at Linköping University Institutional Repository (DiVA):

http://urn.kb.se/resolve?urn=urn:nbn:se:liu:diva-170064

N.B.: When citing this work, cite the original publication.

Bruno, V., Lindau, R., Jenmalm, M., Ticconi, C., Piccione, E., Pietropolli, A., Ernerudh, J., (2020), First-trimester trophoblasts obtained by chorionic villus sampling maintain tolerogenic and proteomic features in successful pregnancies despite a history of unexplained recurrent pregnancy loss, American Journal of Reproductive Immunology, , e13314. https://doi.org/10.1111/aji.13314

Original publication available at:

https://doi.org/10.1111/aji.13314

Copyright: John Wiley and Sons

http://www.wiley.com/ 
Title: First trimester trophoblasts obtained by chorionic villus sampling maintain tolerogenic and proteomic features in successful pregnancies despite a history of unexplained recurrent pregnancy loss.

Running head: Immune profile of ex vivo trophoblasts in RPL

Valentina Bruno a,b,c, Robert Lindau ${ }^{\mathrm{b}}$, Maria C Jenmalm ${ }^{\mathrm{b}}$, Carlo Ticconi ${ }^{\mathrm{c}}$, Emilio Piccione ${ }^{\mathrm{c}}$,

*Adalgisa Pietropolli c, *Jan Ernerudh ${ }^{\mathrm{d}}$

*These authors contributed equally

a Academic Department of Biomedicine and Prevention, Section of Gynecology, Tor Vergata University, Rome, Italy

${ }^{b}$ Department of Biomedical and Clinical Sciences, Linköping University, Linköping, Sweden.

c Academic Department of Surgical Sciences, Section of Gynecology, Tor Vergata University, Rome, Italy

${ }^{\mathrm{d}}$ Department of Clinical Immunology and Transfusion Medicine, and Department of Biomedical and Clinical Sciences, Linköping University, Linköping, Sweden.

Corresponding Author: Valentina Bruno, M.D.

Academic Department of Biomedicine and Prevention, Section of Gynecology and Obstetrics, Tor Vergata University Hospital, Rome, Italy.

Viale Oxford 81, 00133 Rome, Italy

Tel.:+39-6-20902924_E-mail:valentinabruno_86@hotmail.it 


\begin{abstract}
Problem. While there are several known causes for recurrent pregnancy loss (RPL), about 50\% are unexplained (uRPL), and in these cases an aberrant immune regulation seems to be involved. Although fetally derived trophoblast cells have a key role in immune regulation, it is difficult to study their immune function during pregnancy, and it is not known if trophoblast function may be an inherent aberration in URPL or if it is associated with the outcome of the current pregnancy.

Method of study. Chorionic Villus Sampling (CVS) was performed for clinical indications at 12 weeks of gestation. Superfluous materials, divided in small explants, were cultured for $20-24 \mathrm{~h}$, and supernatants (conditioned medium) were collected from 36 women with singleton normal pregnancies, of whom 9 women had a history of RPL. The secreted immune protein profile was measured by proximity extension assay and the conditioned medium was further used in functonal ex vivo models to assess ability to polarize blood monocytes and CD4+ T cells into immune regulatory phenotypes, as detected by flow cytometry.
\end{abstract}

Results. Conditioned medium from chorionic villi, human fetally derived placental tissue, was able to induce a decidual-type of M2 like macrophages, as well as an expansion of Treg cells ex vivo, both in women with uRPL and in control women. The preserved immunological properties were confirmed by a maintained immune protein profile in RPL compared with controls.

Conclusions. Trophoblasts in an ex vivo model maintain tolerogenic and proteomic profile features in successful pregnancies, despite a previous history of RPL.

Keywords: Recurrent pregnancy loss, chorionic villus sampling, proteomics, fetal-maternal immune tolerance, macrophages and regulatory T-cells 


\section{Introduction}

Recurrent pregnancy loss (RPL) is a very distressing early pregnancy complication, which affects 1$3 \%$ of pregnancies (1). There are several known causes for RPL, including parental chromosomal and uterine abnormalities, hormonal factors, major thrombophilia, autoimmune diseases and antiphospholipid antibody syndrome. However, 50-60 \% of RPL are still unexplained (uRPL), and in these cases an aberrant immune regulation is thought to be involved (2). It is not known if the aberrant immune regulation is an inherent general and constant property, or if it is associated with the immune regulation of each pregnancy.

Immune regulation in pregnancy is an interplay between fetal and maternal factors. Fetally derived trophoblast cells infiltrate the decidualized endometrium and have a key role in initiating and maintaining tolerance (3). In order to regulate trophoblast invasion, and to promote fetal tolerance and homeostasis, the decidua is composed of a unique set of immune cells with specialized properties (4). Macrophages and regulatory $\mathrm{T}$ (Treg) cells are both enriched in the decidua, and hold a central position in fetal tolerance establishment (4-6). We have previously demonstrated that fetally derived placental explants were able to induce M2-like macrophages of a decidual phenotype, as well as immunosuppressive Treg cells (3). We further showed that the trophoblasts were the responsible cells for these effects, in part by secretion of M-CSF, IL-10, TGF- $\beta$ and TRAIL. The in vitro model was based on placental tissues from voluntary termination of pregnancy in normal pregnancies. However, it is not known if these properties are maintained when using placental tissue from ongoing pregnancies, and whether the properties may be altered in a pathological condition. In uRPL, a compromised trophoblast function has been suggested $(7,8)$, mainly involving multiple aberrant signal transduction pathways (7,9-21), while their potential immunological dysfunction in uRPL has not been explored. 
Chorionic villus sampling (CVS) offers a possibility for ex vivo studies of trophoblast functions. CVS is an invasive prenatal diagnosis technique, which allows in a very early stage of pregnancy to diagnose potential fetal chromosomal abnormalities, by collecting and analyzing chorionic villi. The superfluous tissue, not used for clinical purposes, can be used for research aims.

This study aims to use CVS as a source of placental tissue from ongoing pregnancies to; (1) evaluate if CVS can be used as an ex vivo model of trophoblast functional aspects; (2) assess whether or not the immune modulatory properties of trophoblasts are maintained in successful pregnancies, despite a history of URPL; and (3) characterize the secreted proteomic profile of placental tissues obtained by CVS.

\section{Materials and Methods}

\section{Subjects}

This prospective study involved 36 pregnant women at 12 weeks of gestation referred to the Prenatal Diagnosis Unit of Tor Vergata University Hospital between 2014 and 2017 in order to undergo CVS. Gestational age was calculated on the basis of the last menstrual period and was confirmed by ultrasonography.

Women were divided into two groups: 27 healthy women with singleton normal pregnancy and without obstetrics complications in their past obstetrical history, and 9 women with a history of RPL, now presenting with a singleton normal pregnancy. RPL was defined as 3 or more consecutive pregnancy losses before 20th week of gestation. Clinical characteristics are presented in Table 1. Since 2 women had minor thrombophilia and 3 had hypothyroidism, these cannot in a strict sense be considered as uRPL, although it is uncertain whether these conditions were causing the RPL (22). In the remaining 4 women in the RPL group, no explanation to RPL was found despite thorough investigation using an extended protocol (23). Among the 27 control women, all samples were used 
in the proteomics assay, while 9 samples were used for functional studies, selected to match samples from the 9 RPL women with regards to age. The total groups (Table 1) were matched for age, BMI, smoking behavior and consistently nullipara were excluded from the study control group. Main indications for CVS in our cohort were: advanced maternal age, defined as $>35$ years of age $(n=26)$, maternal/paternal increased risk for genetic inheritable diseases $(n=2)$, balanced chromosomal abnormalities $(n=3)$ and genetic disease carriers $(n=3)$, ultrasonographic soft markers suspected for chromosomopathies $(n=2)$. No woman in our study had a previous pregnancy with fetal chromosomal abnormalities. All fetuses from pregnancies included in the study had a normal chromosomal map and were negative in a genetic disease test carried out based on the family risk history.

The pregnancies were followed prospectively to assess their outcomes: all women from the two groups had an uncomplicated, at term pregnancy. The study was approved by the Institutional Review Board (protocol number: R.S. 11/16) of Tor Vergata University Hospital, Rome, Italy, and a written consent was obtained before performing CVS from each eligible patient. The healthy control women also signed a written consent before donating blood as approved (M39-08) by the ethics committee in Linköping, Sweden.

\section{CVS technique}

An ultrasound Eidos Hitachi equipped with a transabdominal 3.5-MHz Biopsy Convex Probe was used to guide CVS. All the procedures were done transabdominally by the same expert operator (AP) with the patient placed in a supine position. An $18 \mathrm{G}$ needle was used based on a common clinical protocol approved to obtain a proficient material quality assay. The skin was sterilized with topical application of povidone-iodine. The needle was flushed with $0.5 \mathrm{ml}$ heparin before the procedure. An appropriate site was selected during a preliminary ultrasound examination, and then a needle was introduced under ultrasound guidance until the placenta was reached. Once the needle tip was in place, the stylet was withdrawn and a $10-\mathrm{ml}$ syringe with $5 \mathrm{ml}$ of culture medium was attached to the 
needle hub. Aspirations of chorionic villi were performed in a manual mode. A tissue sample was obtained by moving the plunger of the syringe upward in order to create the discontinuous negative pressure necessary, while the needle was advancing through the chorion. Then the needle was moved forward and backward to obtain adequate specimens from various sites. A check for fetal well being was performed at the end of each procedure. Villous sampling was performed in all cases with a single needle insertion and an amount of about $50 \mathrm{mg}$ of sample (range 40-60) was sent for cytogenetic analysis. Superfluous material, which remains after the routinely clinical investigations, has been used as explants to collect the conditioned medium.

\section{CVS explants culture}

Immediately after CVS collection, the decidua was removed, and the fetal placental tissue was processed. The fetal part of the placenta (simply called "placenta" in this paper) was rinsed with sterile saline to remove traces of maternal blood, and washed in sterile PBS. The CVS specimens were handled according to our previous protocol for placental explants (3), thus dissected and placed in 24-well plates with culture medium consisting of RPMI 1640 (Life Technologies-Invitrogen, Burlington) supplemented with 10\% heat-inactivated fetal bovine serum (FBS) (PAA Laboratories, Paris, France) and 1\% PEST/L-glutamine (Life Technologies- Invitrogen). A total of 50-100 mg of wet tissue was added to each well, pre-filled with $10 \mu 1$ culture medium/mg tissue. The CVS explants were incubated for $20-24 \mathrm{~h}$ at $37^{\circ} \mathrm{C}$ and $5 \% \mathrm{CO}_{2}$. The conditioned medium $(\mathrm{CM})$ was collected, centrifuged, and stored in aliquots at $-70^{\circ} \mathrm{C}$.

\section{Functional studies of macrophages and $T$ cells.}

For the ex vivo assays, blood samples were collected at Linköping University Hospital (Linköping, Sweden) from 9 healthy non-pregnant female volunteers, between 18-45 years of age, not taking hormonal contraceptives or any other medication. A written informed consent was obtained from all 
subjects. All experiments were performed in accordance with the Helsinki Declaration ethical principles for medical research.

\section{Isolation of blood cells}

Peripheral blood mononuclear cells (PBMCs) were isolated on a LymphoPrep gradient (Axis-Shield, Dundee, Scotland, UK), according to the manufacturer's instructions, followed by washing inHBSS (Invitrogen). Isolated PBMCs were used for isolation of $\mathrm{CD} 14^{+}$monocytes or $\mathrm{CD}^{+} \mathrm{T}$ cells by positive selection using immunomagnetic cell sorting. PBMCs were resuspended in sterile MACS buffer (phosphate buffer saline (PBS) supplemented with 2 mM EDTA (Sigma-Aldrich, Saint Louis, Missouri, USA) and $0.5 \%$ fetal bovine serum (FBS)), and the $\mathrm{CD}_{1} 4^{+}$or $\mathrm{CD}^{+}$cells were isolated with anti-CD14 or anti-CD4 mAb-coated MicroBeads, according to the manufacturer's protocol, using MS MACS columns (all from MiltenyiBiotec, BergischGladbach, Germany).

\section{Cell cultures of macrophages and $\mathrm{CD4}^{+} \mathrm{T}$ helper cells}

To analyze the effects of CVS-CM on Treg induction and macrophage polarization, CVS-CM was added to either $\mathrm{CD}^{+}$Th cells at the concentration of $12.5 \%$ or macrophage cultures at two different concentrations: $12 \%$ and $25 \%$. The models of macrophage and Th cell activation and polarization have been optimized and used in previous studies from our group $(3,24,25)$.

Macrophages were generated from $\mathrm{CD}_{14}{ }^{+}$monocytes, as previously described $(3,24)$ with the exception of using 96-well instead of 24-well plates, and corresponding adjustments of cell numbers. Recombinant human granulocyte-macrophage colony-stimulating factor (GM-CSF, $5 \mathrm{ng} / \mathrm{ml}$ ) or macrophage colony-stimulating factor (M-CSF, $50 \mathrm{ng} / \mathrm{ml}$ ) (both from PeproTech, Rocky Hill, United States) were used as basic growth factors with or without adding CVS-CM. Cells were cultured at a density of 100,000 cells/well in $100 \mu \mathrm{l}$ cell culture medium for $6 \mathrm{~d}$ at $37^{\circ} \mathrm{C}$ and $5 \% \mathrm{CO}_{2}$. TrypLE enzyme was used to detatch macrophages from the bottom of the plates. In macrophage cultivation 
experiments, cells from 9 RPL women and 9 healthy controls were used, and exposed to GM-CSF, M-CSF, $12 \%$ CVS-CM and 25\% CVS-CM in the same experiment.

To analyze the effects of CVS-CM on Th cells, isolated $\mathrm{CD}^{+} \mathrm{T}$ cells were cultured as previously described (3), in the presence or absence of CVS-CM, at a density of 100,000 cells/well in $100 \mu 1 \mathrm{~T}$ cell culture medium, consisting of IMDM (Invitrogen) supplemented with L-glutamine (292 mg/ml; Sigma-Aldrich), sodium bicarbonate (3.024 g/l; Sigma-Aldrich), penicillin (50 IE/ml), streptomycin (50 mg/ml) (Cambrex Corporation, East Rutherford, NJ, USA), 100× nonessential amino acids (10 ml/1; Invitrogen), 5\% heat-inactivated $\mathrm{FBS}$, for $3 \mathrm{~d}$ at $37{ }^{\circ} \mathrm{C}$ and $5 \% \mathrm{CO}_{2}$. In $\mathrm{T}$ cell experiments, cells from 9 RPL patients and 9 healthy controls were used.

\section{Flow cytometry staining and analysis}

Cells were resuspended in PBS supplemented with 0.1\% FBS (PBS 0.1\% FBS) and stained with Abs for extracellular staining and their corresponding isotype controls (for Ab details, see Supplemental Table I) for $30 \mathrm{~min}$ at $4{ }^{\circ} \mathrm{C}$ in the dark. PBS $0.1 \% \mathrm{FBS}$ was added, followed by centrifugation at $500 \mathrm{~g}$ for 5 min. The cell pellet was resuspended in PBS $0.1 \%$ FBS for final flow cytometric analysis. LIVE/DEAD ${ }^{\mathrm{TM}}$ Fixable Aqua Dead Cell Staining (TermoFisher Scientific) was used to assess cell viability, according to manufacturer's instructions. After extracellular staining, cells were permeabilized by using the Foxp3 staining kit (eBioscience), followed by staining with anti-human Foxp3 (for Ab details, see Supplemental Table I) for $30 \mathrm{~min}$ at $4{ }^{\circ} \mathrm{C}$. After washing, cells were resuspended in PBS 0.1\% FBS. Data were acquired using a FACSCanto II and analyzed with FACSDiva software version 6.1.2 (BD Biosciences) or Kaluza software version 1.1 (Beckman Coulter, Fullerton, California). Isotype controls were used to set the cut-off for macrophage markers. The $\mathrm{CD} 25^{\text {high }}$ gate was set according to a slightly lowered expression of CD4 on $\mathrm{CD} 4^{+}$cells $\left(\mathrm{CD} 4^{\mathrm{dim}}\right)$ $(25)$.

\section{Proteomics assay}


The Olink ${ }^{\circledR}$ Inflammation panel kit (https:/www.olink.com) was used for the proteomics assay of CVS-CM. This panel includes 92 inflammation-related protein biomarkers, involved in several biological processes. as categorized by GO terms; apoptotic processes, cell activation, cell adhesion, cellular response to cytokine stimulus, chemotaxis, extracellular matrix organization, inflammatory response, MAPK cascade, regulation of immune response, response to hypoxia and secretion.

The Olink ${ }^{\circledR}$ technology is based on the proximity extension assay (PEA). In the first step, 92 oligonucleotide labeled antibody pairs bind their target proteins. If the pair of antibodies bind their protein in close proximity, a hybridization of the reporter oligonucleotides takes place. The product is amplified and detected by real-time qPCR. Thus, the requirement of dual antibody binding secures a high specificity and the PCR amplification secures a high sensitivity of the PEA.

Protein levels are linearized on a log2 scale and expressed as Normalized Protein eXpression(NPX) units. The detection limit was defined as $3 \mathrm{SD}$ above the background. For proteins under the lower limit of detection, half of the detection limit value was assigned to the samples. Proteins with more than $50 \%$ of values under the detection limit were excluded from the analysis (CCL11, CCL19, CCL25, CD6, CX3CL1, FGF-5, FGF-23, IL2, IL4, IL5, IL7, IL-10RA, IL13, IL-15RA, IL-17A, IL17C, IL-20, IL-22RA1, NRTN, NT-3, SLAMF1, TRANCE). Included proteins, which were detected in more than $50 \%$ of the samples, are listed in Figure 3. All samples were analyzed by the Clinical Biomarker Facility Unit at SciLifeLab in Uppsala, Sweden. In the proteomics assay, CM from 9 RPL patients and 27 healthy controls were used.

\section{Data analysis and statistics}

Kolmogorov-Smirnov test was used to analyze data distribution. The majority of the flow cytometry and proteomics data was normally distributed and therefore analyzed with parametric tests. One-way ANOVA followed by the Sidak's post hoc test for paired data was used to compare flow cytometry data, and two-tailed Student's t-test was used to compare protein levels, in women with and without a history of RPL. The Pearson's test was used for testing of correlations between parameters. 
Differences were considered statistically significant for $\mathrm{p}$ value $<0.05$. Data are expressed as mean and standard deviation (SD). All data were analyzed using GraphPad Prism version 8.2.0 (La Jolla, CA, USA).

\section{Results}

\section{Effects of CVS-CM on macrophages polarization}

To assess the effects of CVS-CM on macrophage polarization, CD14+ blood monocytes, isolated from non-pregnant healthy women, were cultured with GM-CSF in the presence or absence ofCVSCM. GM-CSF was used to induce an M1-like phenotype (mainly pro-inflammatory), in order to asses if CVS-CM can reverse the M1 phenotype and increase expression of M2 phenotype markers. GMCSF-macrophages generated in the presence of $12 \%$ and 25\% CVS-CM, both from controls and RPL patients, acquired an M2 decidual macrophage-like phenotype with increased proportions of cells expressing CD14, CD163, CD209, while the proportion of $\mathrm{CD}^{+} 6^{+}$cells was lower (statistically significant at 25\% CVS-CM in the control group), compared with GM-CSF-macrophages not exposed to CVS-CM. The proportions of cells expressing CD206 and HLA-DR were not affected by CVS-CM. The polarization effect was more prominent with 25\% CVS-CM (Figure 1). However, no differences were found when comparing CVS-CM from women with RPL to CVS-CM from controls. No differences were found in the viability of the macrophages across the different groups (data not shown). M-CSF was used as a control for M2 polarization, and always induced a CD14 ${ }^{\text {high }}, \mathrm{CD}_{163^{+}}$, CD209+ population (data not shown).

\section{Effects of CVS-CM on Treg cell induction}

To assess the effects of CVS-CM on Th cells, we cultured $\mathrm{CD}^{+}{ }^{+} \mathrm{T}$ cells from healthy non-pregnant women in the presence or absence of CVS-CM. $\mathrm{CD}^{+} \mathrm{T}$ cells exposed to CVS-CM showed an 
increased proportion of CD25 $5^{\text {highFoxp }} 3^{+}$Treg cells (Figure 2), both from controls and RPL patients. No differences were found in CD25 $5^{\text {high } F o x p} 3^{+}$Treg cells proportions, when exposed to control CVSCM versus RPL CVS-CM. No differences were found in Treg cell viability across the different groups (data not shown). Furthermore, since there was a variation in induction level, we tested but found no correlations between induction levels of CD25 $5^{\text {high }}$ Foxp3-expressing Treg cells and CD163-expressing macrophages, indicating that there is no general defect in quality of the tissues since they are able to influence at least one of the two cell types.

\section{Proteomics data}

For 22 of the 92 proteins, undetectable levels were observed in more than $50 \%$, as described above (Methods). Among the remaining 70 proteins, no differences were found between CVS-CM from controls and women with RPL. The levels of the measurable proteins are presented in Figure 3.

\section{Discussion}

We have shown that conditioned medium from normal pregnancy chorionic villi, human fetally derived placental tissue consisting of trophoblast cells, are able to induce an M2 like-phenotype and an expansion in the Treg population in an ex vivo model. These immunological properties are maintained in women with RPL. In line with this, the inflammation proteomic profile did not differ between the RPL and the control group.

The finding that CM from fetal tissues was able to induce an M2-like and Treg polarization profile is in agreement with our previous findings (3), showing the important function of trophoblast cells to induce a tolerant and homeostatic environment at the maternal side (4-6,24,26-33). Of note, CM from women with RPL did not differ compared with controls, neither in functional aspects, nor in the 
proteomic profile. This may seem to be an unexpected finding since a dysregulation in trophoblasts function in RPL has been suggested in previous studies. However, there are several possible explanations for the lack of aberrations in RPL. It may be that the fetal/placental side is not dysfunctional in RPL, and from our study we cannot exclude dysfunction at the maternal side $(34,35)$. It should also be noted that these patients have already gone beyond the 12 weeks of gestation, and therefore they succeeded in carrying on the pregnancy beyond the highest incidence period, since miscarriages in RPL mostly occur earlier, with peaks at 6 and 8 weeks (36,37). Accordingly, previous studies showing a dysregulation in trophoblast functions were carried out in tissues collected before the $12^{\text {th }}$ of gestation. Furthermore, it has been shown that there is an immunological memory acquired for each pregnancy $(38,39)$, and if no etiological causes can be identified for RPL, the general prognosis of subsequent pregnancies for unexplained RPL is good $(40,41)$. It should be taken into account that unexplained/idiopathic RPL could be considered as a chance occurrence given the high general frequency of pregnancy losses (42). Saravelos et al. (43) stratify idiopathic RPL patients in two subgroups, women with RPL that probably has occurred predominantly by chance, without any specific underlying pathology, and women with uRPL that occur due to an underlying pathology. While the first group has a good prognosis for subsequent pregnancy live birth, conversely the second one has a poorer prognosis. It could therefore be that in our study we unwittingly selected patients included in the first group due to the study design, since CVS is performed after the 12 weeks of gestation, when the major incidence of miscarriage had already passed, and all of them has, therefore, an uncomplicated, at term pregnancy. Taken together, the similar functional and proteomic properties of trophoblast cells from RPL and control women show that beneficial functional effects are associated with a successful pregnancy, arguing against an inherent and constant trophoblast dysfunction in RPL.

The ex vivo model we used offers a possibility to investigate local immunological properties in an ongoing pregnancy, where the outcome of the pregnancy will be known. This is in contrast to previous 
studies using materials from terminated pregnancies, both for controls in a setting of voluntary termination of pregnancies when the outcome of the pregnancy is not known, and in missed abortions when it is not known if aberrations occur primary or secondary to the miscarriage. Limitations in using the CVS model include: (1) it is not possible to perform this technique before the $12^{\text {th }}$ week of gestation, when the majority of pregnancy losses occur; (2) CVS is an invasive prenatal diagnostic technique, with strict clinical indications and not widely used in clinical practice. Nevertheless, our ex vivo model has gained a deeper knowledge in local immune regulation and the secreted protein profile of trophoblast cells in successful pregnancies. A potential possibility would be to use CVS specimens from women that turn out to have a later complication during pregnancy, and thereby reveal aberrations in trophoblast function that could lead to subsequent immune pathology. Indeed, this approach was previously implemented, and revealed immunological aberrations in the first trimester of women that later developed gestational hypertension (35).

The protein profiling data support the preserved immunological trophoblast function in RPL condition, since surprisingly no differences at all were found in the inflammation proteomics panel between controls and RPL. For protein profiling, we used a new technique, PEA, which combines a high specificity with a high sensitivity (44), thus providing reliable mapping of secreted (and not secreted) proteins by trophoblast cells from normal pregnancy. As expected, several of the undetectable proteins are linked to T-cells; IL-2, IL-4, IL-5, IL-13, IL-17A, IL-17C, IL-22RA, and CD6. These results are in line with our previous study, in which IL-13 and IL-17A, associated with Th2 and Th17 cells, respectively, were not produced by fetally derived placental tissue (3). According to the traditional paradigm, a successful pregnancy is associated with a skewed immune response towards a Th2 and Treg associated profile $(6,29-32)$. Nevertheless, in contrast to the traditionally proposed concept to consider pregnancy a Th2 phenomenon (45), the polarization of decidual macrophages and Treg cells seems to be driven by a general and Treg-associated tolerogenic microenvironment, rather than being driven by Th2 cells. This revised concept is supported by the 
following: (1) IL4 and IL13-induced macrophages have a different phenotype from decidual macrophages (24), (2) Treg cells rather than Th2 cells are enriched in the first-trimester decidua (46), (3) IL-10 levels are higher at the fetal-maternal interface, compared with IL-4 and IL-13, as shown previously $(3,47)$, and supported by the present findings Interestingly, IL-20, which has proinflammatory activities that are antagonized by IL-10, one of the key factors responsible for the establishment of a tolerant uterine environment (48), was undetectable in CVS-CM. Accordingly, IL10 was detectable in CVS-CM in our analysis, which is in line with a IL-10- induced function in polarizing homeostatic macrophages and Tregs, in agreement with our previous functional studies (3). The trophoblast-induced macrophages phenotype is induced not only by IL-10, but also by MCSF, which is to a high extent produced by trophoblast cells (3), confirmed in our present study. Furthermore, we previously reported (3) that placental explants/trophoblast cells from terminated $1^{\text {st }}$ trimester pregnancies were able to expand Treg cells in vitro by a co-adjuvant action of IL-10, TGF- $\beta$ and the apoptosis-inducing factor TRAIL $(49,50)$. We here confirm the secretion of these factors in our ex-vivo model of trophoblast cells from CVS-CM. The mechanism of TRAIL-induced Treg expansion seems to be inhibition of the non-Treg cell pool expansion in a mouse model (50). In addition, LIF, another important factor for fetal-maternal tolerance and involved in the induction of Treg cells $(51,52)$, was found to be present in our protein profiling of CVS-CM.

CCL2 was among the top secreted proteins. CCL2 is highly produced also by decidual macrophages (24), as well as by trophoblasts, as we showed previously (3). CCL2 is able to recruit and activate Th2 cells and is involved in M2-associated fetal-maternal tolerance, by reducing production of proinflammatory cytokines from macrophages $(24,53)$. CCL20 and CXCL1 were also detectable in our proteomic CVS-CM profile; these chemokines are both induced by IL-17, and CCL20, in turn, is responsible for Th17 cells recruitment (24)(54-58). The Th17/Treg cells ratio paradigm is crucial also in a pregnancy immune setting, and enhanced Th17 or reduced Treg cells responses have been associated with pregnancy complications, such as recurrent pregnancy loss, preterm birth and 
preeclampsia (32). Nevertheless, Th17 and Treg cells show a wide extent of plasticity in different “inflammatory frameworks", so that they can switch to one another (32). At a lower level of detection, also Th1-associated proteins were detected in the CVS-CM profile, including IFN- $\gamma$ andCXCL9-11, which emphasizes that controlled inflammation takes part in the fetal-maternal regulatory process. Indeed, CXCL9-11 are involved in the recruitment of NK-cells (59), which are abundant in the decidua, and in turn regulate trophoblast invasion (60). It should be pointed out that information acquired by our CVS-CM proteomic panel offers a library for confirming presence of trophoblastderived proteins and further functional studies in fetal-maternal immune tolerance, both regarding well-known, as well as new potential regulatory proteins in physiological and pathological condition in pregnancy.

\section{Conclusions}

(1) An ex vivo model based on CVS-derived trophoblasts was established for evaluation of immune properties and profiling of secreted proteins. (2) Trophoblasts maintained their tolerogenic and proteomic profile features in successful pregnancies, despite a history of RPL. (3) The proteomic profile confirmed the secretion of several central immune regulatory proteins and displayed new candidate regulatory proteins.

\section{Acknowledgments}

The study was supported by the Swedish Research Council grant 2018-02776, ALF grants (Jan Ernerudh), Linköping University and by Tor Vergata University “Mission Sustainability 2017” grant received for the research Project "IKiRM" (Inflammatory and oxidant trophoblastic factors 
expression in unexplained recurrent miscarriage). We would like to acknowledge the support of the Clinical Biomarker Facility at SciLifeLab Sweden for providing excellent assistance in protein analyses.

\section{Declaration of interest statement}

The authors declare that no competing financial interests or any other conflicts of interest exist.

\section{References}

1. Definitions of infertility and recurrent pregnancy loss: A committee opinion. Fertil Steril. 2013;

2. Christiansen OB, Steffensen R, Nielsen HS, Varming K. Multifactorial etiology of recurrent miscarriage and its scientific and clinical implications. Gynecologic and Obstetric Investigation. 2008.

3. Svensson-Arvelund J, Mehta RB, Lindau R, Mirrasekhian E, Rodriguez-Martinez H, Berg G, et al. The human fetal placenta promotes tolerance against the semiallogeneic fetus by inducing regulatory T cells and homeostatic M2 macrophages. J Immunol [Internet]. 2015 Feb 15 [cited 2017 Mar 12];194(4):1534-44. Available from: http://www.jimmunol.org/lookup/doi/10.4049/jimmunol.1401536

4. Svensson-Arvelund J, Ernerudh J, Buse E, Cline JM, Haeger J-D, Dixon D, et al. The placenta in toxicology. Part II: Systemic and local immune adaptations in pregnancy. Toxicol Pathol [Internet]. 2014 Feb 26 [cited 2017 Mar 12];42(2):327-38. Available from: http://journals.sagepub.com/doi/10.1177/0192623313482205

5. Svensson-Arvelund J, Ernerudh J. The Role of Macrophages in Promoting and Maintaining Homeostasis at the Fetal-Maternal Interface. Am J Reprod Immunol [Internet]. 2015 Aug [cited 2017 Mar 12];74(2):100-9. Available from: http://doi.wiley.com/10.1111/aji.12357 
6. Ernerudh J, Berg G, Mjösberg J. Regulatory T helper cells in pregnancy and their roles in systemic versus local immune tolerance. Am J Reprod Immunol [Internet]. 2011 Jul [cited 2017 Mar 12];66 Suppl 1:31-43. Available from: http://doi.wiley.com/10.1111/j.16000897.2011.01049.x

7. Sun Q, Zhang XL. Research on apoptotic signaling pathways of recurrent spontaneous abortion caused by dysfunction of trophoblast infiltration. Eur Rev Med Pharmacol Sci. 2017

8. Brosens I, Pijnenborg R, Vercruysse L, Romero R. The "great Obstetrical Syndromes" are associated with disorders of deep placentation. In: American Journal of Obstetrics and Gynecology. 2011.

9. Wu S, Zhang H, Tian J, Liu L, Dong Y, Mao T. Expression of kisspeptin/GPR54 and $\mathrm{PIBF} / \mathrm{PR}$ in the first trimester trophoblast and decidua of women with recurrent spontaneous abortion. Pathol Res Pract. 2014;

10. Li S, Zhai J, Liu J, Hong Y, Zhao W, Zhao A, et al. BMAL1 facilitates trophoblast migration and invasion via SP1- DNMT1/DAB2IP pathway in recurrent spontaneous abortion.

Oncotarget. 2017;

11. Zhang J, Mo HQ, Tian FJ, Zeng WH, Liu XR, Ma XL, et al. EIF5A1 promotes trophoblast migration and invasion via ARAF-mediated activation of the integrin/ERK signaling pathway. Cell Death Dis. 2018;

12. Tian FJ, Qin CM, Li XC, Wu F, Liu XR, Xu WM, et al. Decreased Stathmin-1 Expression Inhibits Trophoblast Proliferation and Invasion and Is Associated with Recurrent Miscarriage. Am J Pathol. 2015;

13. Wu F, Tian F, Zeng W, Liu X, Fan J, Lin Y, et al. Role of peroxiredoxin2 downregulation in recurrent miscarriage through regulation of trophoblast proliferation and apoptosis. Cell Death Dis. 2017;

14. Canda MT, Caglayan LD, Demir N, Ortaç R. Increased C4d and Bb immunoreactivity and 
decreased MBL immunoreactivity characterise first-time pathologic first-trimester miscarriage: a case-control study. J Obstet Gynaecol (Lahore). 2018;

15. Wang Z, Liu M, Nie X, Zhang Y, Chen Y, Zhu L, et al. NOD1 and NOD2 control the invasiveness of trophoblast cells via the MAPK/p38 signaling pathway in human firsttrimester pregnancy. Placenta. 2015;

16. Wang Y, Liu HZ, Liu Y, Wang HJ, Pang WW, Zhang JJ. Disordered p53-MALAT1 pathway is associated with recurrent miscarriage. Kaohsiung J Med Sci. 2019;

17. Ding J, Cheng Y, Zhang Y, Liao S, Yin T, Yang J. The miR-27a-3p/USP25 axis participates in the pathogenesis of recurrent miscarriage by inhibiting trophoblast migration and invasion. J Cell Physiol. 2019;

18. Li X, Ma XL, Tian FJ, Wu F, Zhang J, Zeng WH, et al. Downregulation of CCNA2 disturbs trophoblast migration, proliferation, and apoptosis during the pathogenesis of recurrent miscarriage. Am J Reprod Immunol. 2019;

19. Ahn JH, Park HR, Park CW, Park DW, Kwak-Kim J. Expression of TWIST in the firsttrimester trophoblast and decidual tissue of women with recurrent pregnancy losses. In: American Journal of Reproductive Immunology. 2017.

20. Unverdorben L, Haufe T, Santoso L, Hofmann S, Jeschke U, Hutter S. Prototype and chimera-type galectins in placentas with spontaneous and recurrent miscarriages. Int J Mol Sci. 2016;

21. Dong X, Yang L, Wang H. miR-520 promotes DNA-damage-induced trophoblast cell apoptosis by targeting PARP1 in recurrent spontaneous abortion (RSA). Gynecol Endocrinol. 2017

22. Society E, Reproduction H, November E, Early E, Guidline P, Group D. RECURRENT PREGNANCY LOSS Guideline of the European Society of Human Reproduction and Embryology. ESHRE Early Pregnancy Guid Dev Gr. 2017;

23. Bruno V, Rizzacasa B, Pietropolli A, Capogna MV, Massoud R, Ticconi C, et al. OLR1 and 
loxin expression in PBMCs of women with a history of unexplained recurrent miscarriage: A pilot study. Genet Test Mol Biomarkers [Internet]. 2017 Jun [cited 2019 Jun 16];21(6):36372. Available from: http://www.liebertpub.com/doi/10.1089/gtmb.2016.0331

24. Svensson J, Jenmalm MC, Matussek A, Geffers R, Berg G, Ernerudh J. Macrophages at the fetal-maternal interface express markers of alternative activation and are induced by M-CSF and IL-10. J Immunol [Internet]. 2011 Oct 1 [cited 2017 Mar 12];187(7):3671-82. Available from: http://www.jimmunol.org/cgi/doi/10.4049/jimmunol.1100130

25. Mjösberg J, Svensson J, Johansson E, Hellström L, Casas R, Jenmalm MC, et al. Systemic reduction of functionally suppressive CD4dimCD25highFoxp3+ Tregs in human second trimester pregnancy is induced by progesterone and 17beta-estradiol. J Immunol [Internet]. 2009 Jul 1 [cited 2017 Mar 12];183(1):759-69. Available from: http://www.jimmunol.org/cgi/doi/10.4049/jimmunol.0803654

26. Nancy P, Tagliani E, Tay C-S, Asp P, Levy DE, Erlebacher A. Chemokine gene silencing in decidual stromal cells limits T cell access to the maternal-fetal interface. Science [Internet]. 2012 Jun 8 [cited 2018 Sep 12];336(6086):1317-21. Available from:

http://www.sciencemag.org/cgi/doi/10.1126/science.1220030

27. Vento-Tormo R, Efremova M, Botting RA, Turco MY, Vento-Tormo M, Meyer KB, et al. Single-cell reconstruction of the early maternal-fetal interface in humans. Nature [Internet]. 2018 Nov 14 [cited 2019 Jun 16];563(7731):347-53. Available from: http://www.ncbi.nlm.nih.gov/pubmed/30429548

28. Sasaki Y, Sakai M, Miyazaki S, Higuma S, Shiozaki A, Saito S. Decidual and peripheral blood CD4 $+\mathrm{CD} 25+$ regulatory $\mathrm{T}$ cells in early pregnancy subjects and spontaneous abortion cases. Mol Hum Reprod. 2004;

29. Saito S, Nakashima A, Shima T, Ito M. Th1/Th2/Th17 and Regulatory T-Cell Paradigm in Pregnancy. Am J Reprod Immunol. 2010;63(6):601-10.

30. Robertson SA, Care AS, Moldenhauer LM. Regulatory T cells in embryo implantation and 
the immune response to pregnancy The Journal of Clinical Investigation. J Clin Invest. 2018;128(10):4224-35.

31. Ernerudh J, Berg G, Mjösberg J. Regulatory T helper cells in pregnancy and their roles in systemic versus local immune tolerance. Am J Reprod Immunol. 2011;66(SUPPL. 1):31-43.

32. Figueiredo AS, Schumacher A. The T helper type 17/regulatory T cell paradigm in pregnancy. Immunology [Internet]. 2016 May [cited 2018 Sep 12];148(1):13-21. Available from: http://doi.wiley.com/10.1111/imm.12595

33. Nancy P, Erlebacher A. T cell behavior at the maternal-fetal interface. Int J Dev Biol [Internet]. 2014 [cited 2018 Sep 12];58(2-3-4):189-98. Available from: http://www.ncbi.nlm.nih.gov/pubmed/25023685

34. Ticconi C, Pietropolli A, Di Simone N, Piccione E, Fazleabas A. Endometrial immune dysfunction in recurrent pregnancy loss. International Journal of Molecular Sciences. 2019.

35. Prins JR, Faas MM, Melgert BN, Huitema S, Timmer A, Hylkema MN, et al. Altered expression of immune-associated genes in first-trimester human decidua of pregnancies later complicated with hypertension or foetal growth restriction. Placenta. 2012;

36. Bruno V, Ticconi C, Sarta S, Piccione E, Pietropolli A. What has to be pointed out in unexplained recurrent pregnancy loss research in the unsolved fields: lessons from clinic. An Italian RPL Unit experience. Ital J Gynaecol Obstet. 2019;31(N. 2).

37. Ticconi C, Giuliani E, Sorge R, Patrizi L, Piccione E, Pietropolli A. Gestational age of pregnancy loss in women with unexplained recurrent miscarriage. J Obstet Gynaecol Res. 2016

38. Gamliel M, Goldman-Wohl D, Isaacson B, Gur C, Stein N, Yamin R, et al. Trained Memory of Human Uterine NK Cells Enhances Their Function in Subsequent Pregnancies. Immunity. 2018

39. Rowe JH, Ertelt JM, Xin L, Way SS. Pregnancy imprints regulatory memory that sustains anergy to fetal antigen. Nature. 2012; 
40. Clifford K, Rai R, Regan L. Future pregnancy outcome in unexplained recurrent first trimester miscarriage. Hum Reprod. 1997/02/01. 1997;12(2):387-9.

41. The ESHRE Guideline Group on RPL., Bender Atik R, Christiansen OB, Elson J, Kolte AM, Lewis S, et al. ESHRE guideline: recurrent pregnancy loss. Hum Reprod Open. 2018 Apr;2:hoy004-hoy004.

42. Vlaanderen W. Is recurrent miscarriage a useful clinical concept? Acta Obstet Gynecol Scand. 2014;

43. Saravelos SH, Li TC. Unexplained recurrent miscarriage: How can we explain it? Human Reproduction. 2012.

44. Benson MD, Ngo D, Ganz P, Gerszten RE. Emerging affinity reagents for high throughput proteomics. Circulation. 2019.

45. Wegmann TG, Lin H, Guilbert L, Mosmann TR. Bidirectional cytokine interactions in the maternal-fetal relationship: is successful pregnancy a TH2 phenomenon? Immunology Today. 1993.

46. Mjösberg J, Berg G, Jenmalm MC, Ernerudh J. FOXP3+ regulatory T cells and T helper 1, T helper 2, and T helper 17 cells in human early pregnancy decidua. Biol Reprod [Internet]. 2010 Apr 1 [cited 2017 Mar 12];82(4):698-705. Available from: https://academic.oup.com/biolreprod/article-lookup/doi/10.1095/biolreprod.109.081208

47. Hanna N, Hanna I, Hleb M, Wagner E, Dougherty J, Balkundi D, et al. Gestational AgeDependent Expression of IL-10 and Its Receptor in Human Placental Tissues and Isolated Cytotrophoblasts. J Immunol. 2000;

48. Hsieh MY, Chen WY, Jiang MJ, Cheng BC, Huang TY, Chang MS. Interleukin-20 promotes angiogenesis in a direct and indirect manner. Genes Immun. 2006;

49. Stenqvist A-C, Nagaeva O, Baranov V, Mincheva-Nilsson L. Exosomes Secreted by Human Placenta Carry Functional Fas Ligand and TRAIL Molecules and Convey Apoptosis in Activated Immune Cells, Suggesting Exosome-Mediated Immune Privilege of the Fetus. J 
Immunol [Internet]. 2013 Dec 1 [cited 2017 Mar 12];191(11):5515-23. Available from: http://www.jimmunol.org/cgi/doi/10.4049/jimmunol.1301885

50. Ikeda T, Hirata S, Fukushima S, Matsunaga Y, Ito T, Uchino M, et al. Dual Effects of TRAIL in Suppression of Autoimmunity: The Inhibition of Th1 Cells and the Promotion of Regulatory T Cells. J Immunol [Internet]. 2010 Nov 1 [cited 2017 Mar 12];185(9):5259-67. Available from: http://www.jimmunol.org/cgi/doi/10.4049/jimmunol.0902797

51. Gao W, Thompson L, Zhou Q, Putheti P, Fahmy TM, Strom TB, et al. Treg versus Th17 lymphocyte lineages are cross-regulated by LIF versus IL-6. Cell Cycle. 2009;

52. Chang Y, De Nadai P, Azzaoui I, Morales O, Delhem N, Vorng H, et al. The chemokine CCL18 generates adaptive regulatory $\mathrm{T}$ cells from memory CD4+ T cells of healthy but not allergic subjects. FASEB J. 2010;

53. Joseph PRB, Sawant K V., Rajarathnam K. Heparin-bound chemokine CXCL8 monomer and dimer are impaired for CXCR1 and CXCR2 activation: implications for gradients and neutrophil trafficking. Open Biol. 2017 Nov;7(11):170168.

54. Park H, Li Z, Yang XO, Chang SH, Nurieva R, Wang YH, et al. A distinct lineage of CD4 T cells regulates tissue inflammation by producing interleukin 17. Nat Immunol. 2005;6(11):1133-41.

55. Griffith JW, Sokol CL, Luster AD. Chemokines and chemokine receptors: positioning cells for host defense and immunity. Annu Rev Immunol. 2014/03/25. 2014;32:659-702.

56. Ekman AK, Sigurdardottir G, Carlström M, Kartul N, Jenmalm MC, Enerbäck C. Systemically elevated Th1-, Th2- and Th17-associated chemokines in psoriasis vulgaris before and after ultraviolet B treatment. Acta Derm Venereol. 2013;93(5):525-31.

57. Annunziato F, Cosmi L, Liotta F, Maggi E, Romagnani S. Defining the human T helper 17 cell phenotype. Trends Immunol [Internet]. 2012;33(10):505-12. Available from: http://dx.doi.org/10.1016/j.it.2012.05.004

58. Mantovani A, Sica A, Sozzani S, Allavena P, Vecchi A, Locati M. The chemokine systemin 
diverse forms of macrophage activation and polarization. Trends Immunol. 2004;25(12):677-86.

59. Bai X xia, Kong B hua, Zhang Y zhong, Qu X, Wang H li. [Expression and significance of chemokine CXC receptor 3, 4 and their ligands at the early pregnancy decidua and villi]. Zhonghua Fu Chan Ke Za Zhi. 2008;

60. Salker MS, Nautiyal J, Steel JH, Webster Z, Sućurović S, Nicou M, et al. Disordered IL33/ST2 activation in decidualizing stromal cells prolongs uterine receptivity in women with recurrent pregnancy loss. Fritz JH, editor. PLoS One [Internet]. 2012 Dec 27 [cited 2017 Mar 12];7(12):e52252. Available from: http://dx.plos.org/10.1371/journal.pone.0052252 
Table 1. Demographic and clinical characteristics

\begin{tabular}{|c|c|c|c|c|}
\hline \multicolumn{2}{|l|}{ 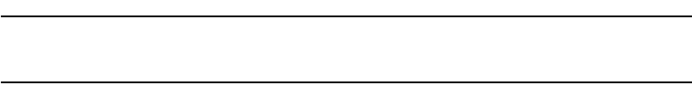 } & $\begin{array}{l}\text { RPL } \\
(n=9)\end{array}$ & $\begin{array}{l}\text { CONTROLS } \\
(n=27)\end{array}$ & $p$ VALUE* \\
\hline \multicolumn{2}{|l|}{ Age (years) } & $37 \pm 4.4$ & $38 \pm 3.2$ & $0.45^{\text {(a) }}$ \\
\hline \multicolumn{2}{|l|}{ BMI $\left(\mathrm{Kg} / \mathrm{m}^{2}\right)$} & $22 \pm 1.4$ & $23 \pm 3.8$ & $0.24^{\text {(a) }}$ \\
\hline \multicolumn{2}{|c|}{ Number of previous miscarriages } & $3.1 \pm 0.3$ & NA & NA \\
\hline \multicolumn{2}{|c|}{ Week for previous miscarriages } & $7 \pm 1.9$ & NA & NA \\
\hline \multicolumn{2}{|c|}{ Previous pregnancy at term } & $3(33)$ & $20(74)$ & $0.04^{\text {(a) }}$ \\
\hline \multicolumn{2}{|l|}{ Smoking } & $1(11)$ & $3(11)$ & $0.99^{\text {(b) }}$ \\
\hline \multicolumn{2}{|c|}{ Minor trombophilia } & $2(22)$ & $1(4)$ & $0.15^{\text {(b) }}$ \\
\hline \multicolumn{2}{|c|}{ Dysthiroidism } & $3(33)$ & 0 & $0.01^{(b)}$ \\
\hline \multicolumn{2}{|c|}{ Celiac disease } & 0 & $1(4)$ & $0.99^{(b)}$ \\
\hline $\begin{array}{l}\text { Therapy } \\
\text { during } \\
\text { pregnancy }\end{array}$ & $\begin{array}{l}\text { Corticosteroids } \\
\text { Progesterone } \\
\text { Low dose aspirin } \\
\text { Thyroid hormones }\end{array}$ & $\begin{array}{l}2(22) \\
2(22) \\
3(33) \\
3(33)\end{array}$ & $\begin{array}{l}0 \\
0 \\
0 \\
1(4)\end{array}$ & $0.035^{(\mathbf{b})}$ \\
\hline $\begin{array}{l}\text { Clinical } \\
\text { indications } \\
\text { for CVS }\end{array}$ & $\begin{array}{l}\text { Maternal age } \\
\text { Previous chromosomal abnormalities } \\
\text { Genetic inheritable diseases } \\
\text { Balanced chromosomal abnormalities } \\
\text { Genetic disease healthy carriers } \\
\text { Ultrasonographic soft markers }\end{array}$ & $\begin{array}{l}5(56) \\
1 \\
0 \\
3(33) \\
0 \\
1(11)\end{array}$ & $\begin{array}{l}21(56) \\
1 \\
2(7) \\
0 \\
3(11) \\
1(4)\end{array}$ & $<0.0001^{\text {(b) }}$ \\
\hline \multicolumn{2}{|c|}{ Gestational week of the delivery } & $39.3 \pm 1.7$ & $39.1 \pm 1.4$ & $0.60^{\text {(a) }}$ \\
\hline \multicolumn{2}{|l|}{ Birth weight } & $3268 \pm 278.1$ & $3334.5 \pm 335.9$ & $0.28^{\text {(a) }}$ \\
\hline
\end{tabular}

Data are expressed as Mean \pm SD or $n(\%)$.

NA. Not Applicable

* Student's t-test ${ }^{(\mathrm{a})}$ or Fisher's exact test ${ }^{(\mathrm{b})}$. 


\section{Figure legends}

Figure 1. Effects of Chorionic villi conditioned medium on macrophage polarization.

Blood monocytes from healthy non-pregnant women were differentiated to macrophages for 6 days with GM-CSF in the absence or presence of $12 \%$ or $25 \%$ chorionic villous sampling conditioned medium from control (ctrl) women $(\mathrm{n}=9)$ and from women with recurrent pregnancy loss (RPL, $\mathrm{n}=9)$. Phenotypic characterization by flow cytometry, expressed as \% of macrophages. Data are shown as mean and S.D. One-way ANOVA and Sidak' s test: ${ }^{*} \mathrm{p}<0.05 ; * * \mathrm{p}<0.005$; all $\mathrm{p}$ values refer to comparisons with GM-CSF only.

\section{Figure 2. Effects of Chorionic villi conditioned medium on regulatory $T$ cells.}

a) CD4+ T-cells isolated from healthy non-pregnant women were cultured 5 days in tissue culture medium (TCM) in the absence or presence of $12 \%$ or $25 \%$ chorionic villous sampling conditioned medium (CVS-CM) from control (ctrl) women $(n=9)$ and from women with recurrent pregnancy loss (RPL, $n=9$ ). Phenotypic characterization of Treg cells by flow cytometry, expressed as \% of CD4+ T-cells. Data are shown as mean and S.D. One-way ANOVA and Sidak's test: ${ }^{*} \mathrm{p}<0.05 ; * * \mathrm{p}<0.005$; all $\mathrm{p}$ values refer to comparisons with tissue culture medium (TCM) only.

b) - c) Bivariate correlations between levels of CD25 highFoxp3-expressing Treg cells and CD163expressing macrophages are shown in panel b) in presence of $12 \%$ of CVS-CM and in panel c) in presence of $25 \%$ of CVS-CM.

Pearson's test: n.s.

Figure 3. Proteomics assay data. 
Levels of detectable immune-related proteins in chorionic villous sampling-conditioned medium (CVS-CM) from controls (c, n=27) and from women with recurrent pregnancy loss (rpl, n=9). Values are expressed as linearized $\log 2$ scale NPX (Normalized Protein eXpression) and sorted by size in the control group. Data are shown as mean and S.D. two-tailed Student's t-test: n.s. 
a)

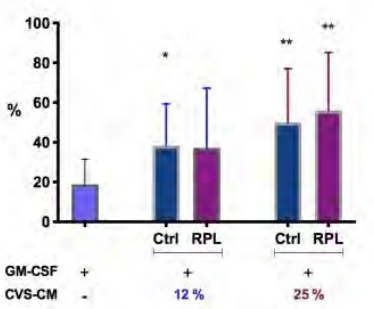

CD206

d)

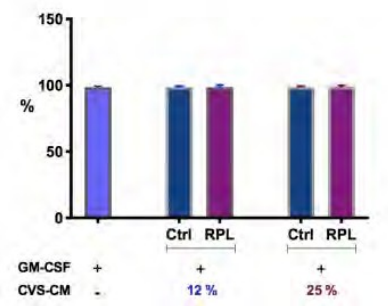

b)

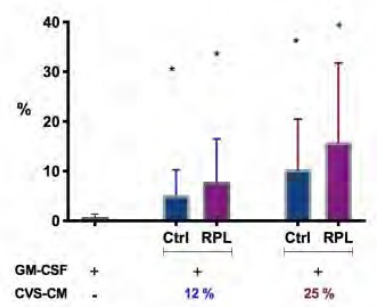

HLA-DR

e)

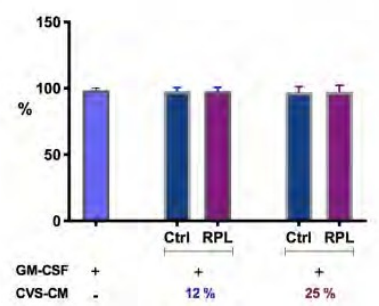

c)
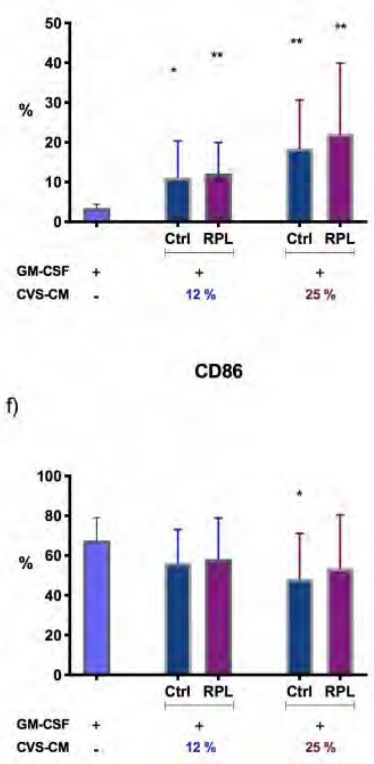

$269 \times 182 \mathrm{~mm}(300 \times 300 \mathrm{DPI})$ 
2

3

4

5

6

7

8

9

10

11

12

13

14

15

16

17

18

19

20

21

22

23

24

25

26

27

28

29

30

31

32

33

34

35

36

37

38

39

40

41

42

43

44

45

46

47

48

49

50

51

52

53

54

55

56

57

58

59

60

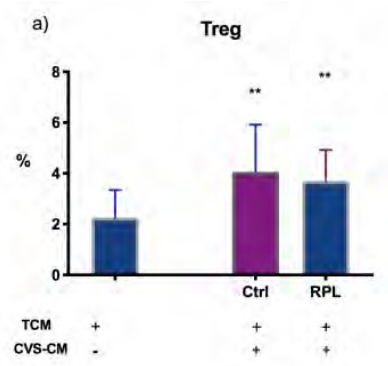

b) Treg/CD163 $12 \%$
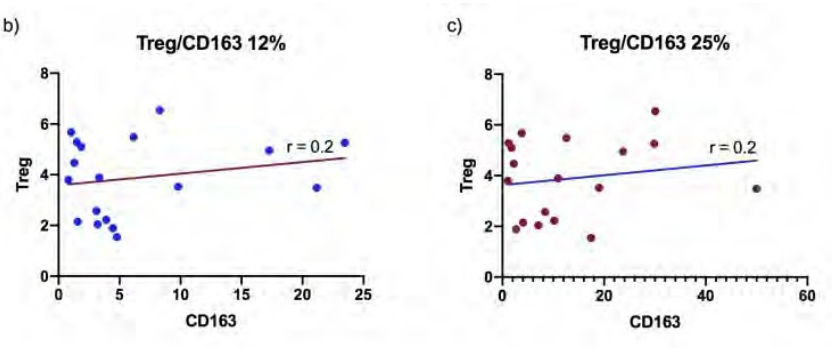

$296 \times 85 \mathrm{~mm}(300 \times 300 \mathrm{DPI})$ 


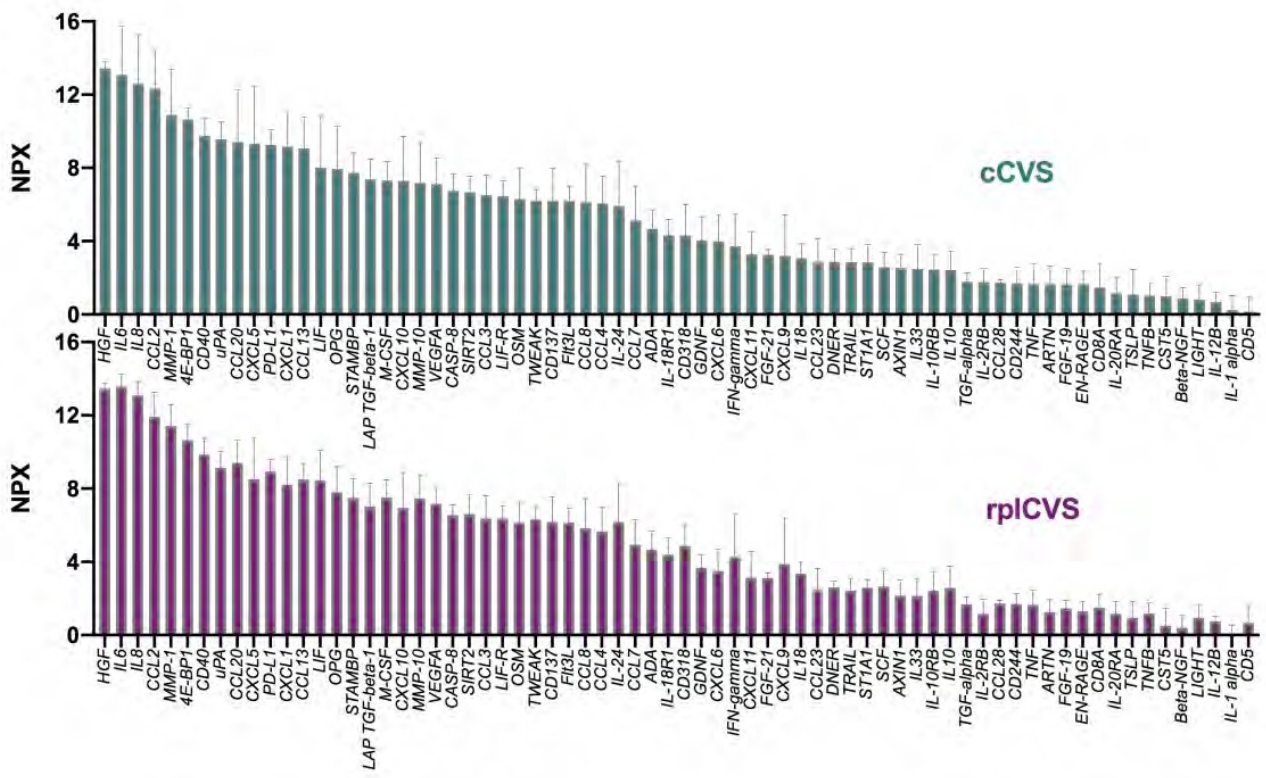

$253 \times 158 \mathrm{~mm}(300 \times 300 \mathrm{DPI})$ 
Supplemental table I. Antibodies used for flow cytometry.

\begin{tabular}{|c|c|c|c|c|c|c|c|}
\hline \multirow{2}{*}{ Cell type } & \multirow{2}{*}{ Antigen } & \multirow[t]{2}{*}{ Isotype } & \multicolumn{2}{|c|}{ Clone } & \multirow[t]{2}{*}{ Fluorochrome } & \multicolumn{2}{|c|}{ Manufacturer } \\
\hline & & & Antigen & Isotype & & Antigen \& Isotype & Clone \\
\hline \multirow[t]{5}{*}{ Macrophages } & HLA-DR & Mouse IgG2b & L243 & $27-35$ & FITC & \multicolumn{2}{|c|}{ BD Biosciences } \\
\hline & CD 163 & Mouse IgG1 & $\mathrm{GHI} / 61$ & $\mathrm{X} 40$ & PE & \multicolumn{2}{|c|}{ BD Biosciences } \\
\hline & CD 206 & Mouse IgG1 & 19.2 & $\mathrm{X} 40$ & APC & \multicolumn{2}{|c|}{ BD Biosciences } \\
\hline & CD 209 & Mouse IgG2b & DCN46 & 2735 & PerCP-Cy5.5 & \multicolumn{2}{|c|}{ BD Biosciences } \\
\hline & CD86 & Mouse IgG1 & 2331/FUN-1 & $\mathrm{X} 40$ & V450 & \multicolumn{2}{|c|}{ BD Biosciences } \\
\hline \multirow[t]{3}{*}{ T helper cells } & CD4 & $\bar{l}$ & SK3 & 1 & FITC & \multicolumn{2}{|c|}{ BD Biosciences } \\
\hline & $\mathrm{CD} 25$ & I & B1.49.9 & / & PC-7 & BioLegend & Beckman Coulter \\
\hline & Foxp3 & I & PCH101 & / & $\mathrm{PE}$ & \multicolumn{2}{|c|}{ eBioscience } \\
\hline
\end{tabular}


